Leandro Coelho Dalvi*, Christiane Laine, Tommi Virtanen, Tiina Liitiä, Tiia-Maria Tenhunen, Hannes Orelma, Tekla Tammelin and Tarja Tamminen

\title{
Study of xylan and cellulose interactions monitored with solid-state NMR and QCM-D
}

https://doi.org/10.1515/hf-2019-0221

Received August 28, 2019; accepted November 5, 2019

\begin{abstract}
Development of physical properties of bleached eucalyptus kraft pulp is typically based on the refining process. However, many studies have reported that xylan deposition is a viable alternative. As the mechanisms of xylan and cellulose interactions are not clear, the main goal of this study was to achieve a better understanding of these interactions. Considering that a sample of pulp enriched with xylan is a very complex matrix, a model system was developed. Cellulosic thin films were prepared by spincoating and the Langmuir-Schaefer (LS) method from trimethylsilylcellulose (TMSC). Their interactions with xylan were analyzed using the quartz crystal microbalance with dissipation (QCM-D) monitoring technique. The topological changes on cellulose were studied using atomic force microscopy (AFM). For the ${ }^{13} \mathrm{C}$ solid-state nuclear magnetic resonance (NMR) studies, samples were prepared using commercial microcrystalline cellulose (MCC) and xylan. The xylan was extracted from bleached birch kraft pulp using a cold caustic extraction (CCE) method. The QCM-D monitoring showed deposition only with higher concentrations of xylan solution $\left(1 \mathrm{mg} \cdot \mathrm{l}^{-1}\right)$ for the LS method. The AFM images showed that xylan deposits as agglomerates on the cellulose surface, and the NMR experiments showed that there are interactions for the more ordered region of the cellulose fiber and for the less-ordered region.
\end{abstract}

Keywords: AFM, cellulose, deposition, NMR, QCM-D, xylan

\footnotetext{
*Corresponding author: Leandro Coelho Dalvi, Celulose NipoBrasileira S.A., CENIBRA, Rodovia BR 381, Km 172, Belo Oriente, MG 35196-972, Brazil, e-mail: leandro.dalvi@cenibra.com.br Christiane Laine, Tommi Virtanen, Tiina Liitiä, Tiia-Maria Tenhunen, Hannes Orelma, Tekla Tammelin and Tarja Tamminen: VTT Technical Research Centre of Finland, P.O Box 1000, Fl-02044 VTT Espoo, Finland
}

\section{Introduction}

Cellulose is the most abundant organic compound in the planet and the main structural component of plant cells. It is a linear polysaccharide formed by $\beta$-D-glucopyranose units linked by $\beta$-1,4-glycosidic covalent bonds (Sjöström 1981). Native cellulose is formed by two crystalline allomorphs, I $\alpha$ and I $\beta$, demonstrated by cross-polarization magic angle spinning (CPMAS) ${ }^{13} \mathrm{C}$ nuclear magnetic resonance (NMR) techniques. Those two allomorphs are different regarding the crystalline structure, hydrogen bonds and molecular conformation (Atalla and Vanderhart 1984).

Hemicelluloses, along with cellulose and pectin, are polysaccharides that form the cell wall of higher plants (Sjöström 1981). Hemicelluloses can be found both in the primary and secondary walls and, in a small amount, in the middle lamella. Hemicelluloses are branched heteropolymers constituted by different monosaccharides in pyranose or furanose forms in different proportions (Timell 1967; Srndovic 2011).

Hemicelluloses are amorphous polymers, without the tendency to form crystalline regions in their native forms on the fiber walls, providing flexibility (Atalla et al. 1993).

It has recently been proposed that xylan might be able to form hydrogen bonds with the hydrophilic surfaces of cellulose through folding as a twofold helical screw (Bromley et al. 2013; Busse-Wicher et al. 2014, 2016a,b) while it adapts a threefold helical screw xylan in solution (Simmons et al. 2016).

Xylans are hemicelluloses easily removed by alkali solutions, due to their amorphous structure and high amount of acid groups typically present as side groups in xylans (Aurell 1965).

The main sources to xylan extraction in a kraft pulp mill are wood chips, cooking liquors and bleached pulp (Axelsson et al. 1962; Simonson 1963; Sjöström and Enström 1967; Janzon et al. 2006; Dahlman et al. 2008; Krogerus and Fuhrmann 2009).

An increase in the amount of hemicelluloses in the fiber wall can be achieved in two different ways: improving the retention of hemicelluloses in the fibers during the delignification process (Kleppe 1970) and conducting 
a deposition process of dissolved hemicellulose polymers onto the fiber (Yllner and Enström 1956; Aurell 1965; Dahlman et al. 2003).

Earlier studies of xylan sorption onto cellulose surfaces have reported first-order kinetics. This indicates a physical process, with Van der Waals or hydrogen bonds between the sorbed xylan and the cellulose substrate (Clayton and Phelps 1965; Hansson 1970; Mora et al. 1986; Mitikka-Eklund, 1996; Danielsson and Lindström 2005; Ribe et al. 2009). Others studies have reported the adsorption of xylan on the cellulose fibers as a relatively slow process, probably due to the molecular diffusion in the porous fiber wall (Clayton and Phelps 1965; Hansson 1970).

Hydrogen bonds have been demonstrated to be involved in the xylan retention during sorption-desorption experiments with hydrogen bond disruptor reagents (Mora et al. 1986). However, the hydrogen bond formation between xylan and cellulose has been questioned. Previous studies have affirmed that if hydrogen bond formation does occur, the xylan layer on the cellulose surface should be flat, according to the models for free energy between flat surfaces (Derjaguin 1934), and not swollen with water as observed in experiments using techniques such as quartz crystal microbalance with dissipation (QCM-D). They suggest, then, that the driving force is a combination of entropy increasing, associated with the release of solvent molecules during the polymer adsorption, and the weak Van der Waals attraction, rather than formation of hydrogen bonds as has been cited before (Mora et al. 1986; Tammelin et al. 2009). Despite that, hydrogen bonds may be important for dried systems (Paananen et al. 2004).

Other studies suggested that xylan exists both as single molecules in aqueous solution and as aggregates in the colloidal size. The aggregate formation is provided by the interaction of unsubstituted regions of the xylan chain and by the hydrophobic interaction due to lignin residues covalently bonded to xylan. Consequently, the adsorption on the cellulose surface happens through single molecules and aggregates. This mechanism is, probably, more relevant for systems in which the xylan solubility is lower (Mora et al. 1986; Linder et al. 2003).

Xylan adsorption is considered as irreversible and only small amounts are removed by dilution (Paananen et al. 2004) or water washing (Eriksson et al. 1963). Exposure to alkaline conditions under high temperatures increases the desorption rate (Hansson and Hartler 1969). It is easy to understand as the solubility of hemicelluloses is higher under alkaline conditions (Miao et al. 2014; Li et al. 2015).
However, it has been reported that adsorbed xylan from cold caustic extraction (CCE) liquors is kept in the cellulose surface even after the delignification process or bleaching sequences (Dahlman et al. 2003; Soares 2009).

The interest of the pulp and paper industry over the xylan content of cellulose pulps is based on the carboxylic groups which are introduced in the cellulose fibers by xylan (Kleppe 1970). Fibers with high xylan content get swollen easily, exposing a higher superficial area, thereby increasing the active sites for fiber reactions (Eriksson and Sjöström 1968; Mobarak et al. 1973). It has been reported that adsorbed xylan on pulp increases tensile properties of the paper (Sihtola and Blomberg 1975; Schönberg et al. 2001) and decreases the energy consumption during the refining process (Aurell 1965; Mobarak et al. 1973; Vaaler et al. 2002).

NMR has been used as an extensive physical method to determine the structure of organic compounds. Developments in high-resolution solid-state NMR of organic materials over the last 30 years have been deeply established (Dybowski and Bai 2006). The materials that are investigated can be natural, synthetic and even biological systems, and ${ }^{13} \mathrm{C}$ is undoubtedly the most feasible nucleus that can be studied with high-resolution NMR in the solid phase. It can be easily observed and the interpretation of ${ }^{13} \mathrm{C}$ spectra is almost a direct reading of the carbon skeleton of molecules (Ghisalberti and Godfrey 1998; Lambert et al. 2000; Alesiani et al. 2005; Pournou 2008; Dupree et al. 2015; Santonia et al. 2015).

The structures of cellulose in wood and pulp have been extensively studied employing CPMAS ${ }^{13} \mathrm{C}$ NMR spectroscopy (Van der Hart and Atalla 1984; Newman and Hemmingson 1990; Newman 1992; Newman et al. 1993; Lindgren et al. 1995; Larsson et al. 1997; Newman 1998; Wickholm et al. 1998; Larsson et al. 1999; Hult et al. 2000; Maunu et al. 2000). Other advanced techniques such as atomic force microscopy (AFM) and QCM-D monitoring have been used as support for a better knowledge of xylan and cellulose interactions (Binnig et al. 1986; Ducker et al. 1991; Fatisson et al. 2009; Thio et al. 2011; Chen et al. 2016; Mocchiuttia et al. 2016; Korolkov et al. 2019).

As there is a great interest in the xylan content from pulp and paper producers, knowledge of the mechanisms of xylan adsorption on cellulose surface is desirable. Therefore, the main goal of this work was to study the interactions of xylan and cellulose using techniques such as ${ }^{13} \mathrm{C}$ solid-state NMR, AFM and QCM-D associated with nanofilm samples to achieve a purer model than the industrial pulp samples. 


\section{Materials and methods}

Xylan samples: Xylan has been extracted from commercial bleached birch kraft pulp using $1 \mathrm{M} \mathrm{NaOH}$ solution at room temperature followed by ultra- and diafiltration as described earlier (Laine et al. 2015) and as shown in Figure 1.

Saturated solutions/dispersions of xylan were prepared, at different $\mathrm{pH}$, from a xylan slurry of dry matter content (DMC) by adding deionized water and $1 \mathrm{M} \mathrm{NaOH}$ solution and regulating the $\mathrm{pH}$ several times during stirring for $48 \mathrm{~h}$ at room temperature. After centrifugation, the supernatants were the samples used for the adsorption trials, according to Figure 2.

The carbohydrate content of the saturated xylan solutions and the DMC were determined (Table 1).

Preparation of cellulose samples with adsorbed xylan: Microcrystalline cellulose (Sigmacell Type 50 S-5504, Sigma-Aldrich Oy, Espoo, Finland) (MCC) was selected as the cellulose model. Xylan isolated from bleached birch kraft pulp was added to the cellulose suspension at selected $\mathrm{pH}$ values, 13 (represents a high $\mathrm{pH}$ during pulp processing) and 10 (where xylan precipitation in practice may take place at the final phase of pulping). Adsorption experiments were performed by mixing soluble/dispersed xylan and MCC at defined conditions.

The DMCs were $95.1 \%$ for MCC and $9.18 \%$ for the original xylan dispersion.

The soluble part of the xylan dispersion was isolated by regulating the $\mathrm{pH}$ of 1.21 of xylan dispersion to $\mathrm{pH} 13$ and $\mathrm{pH} 10$, respectively, and a final xylan content of $2.5 \%$ wt. After stirring at room

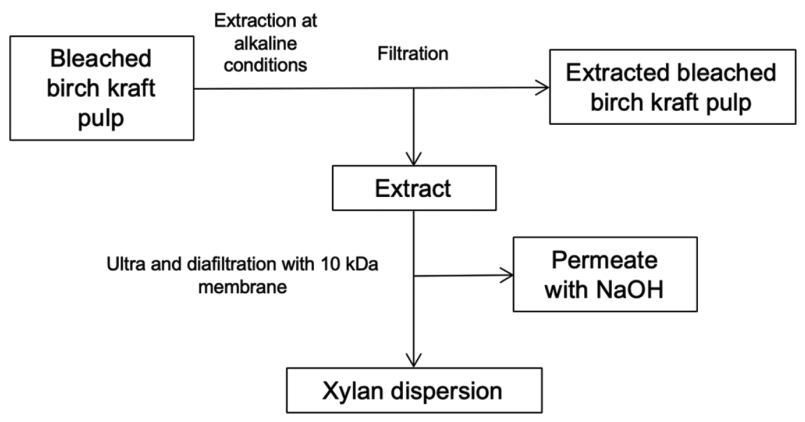

Figure 1: Schematic flow to obtain xylan dispersion according to Laine et al. 2015. temperature for $48 \mathrm{~h}$ and $\mathrm{pH}$ adjustment as necessary, the dispersion/solution was centrifuged at $4750 \mathrm{rpm}(5250 \mathrm{~g})$ for $1 \mathrm{~h}$ at room temperature using an Allegra X-15R (Beckman Coulter, Inc., Brea, CA, USA) centrifuge and the supernatant was collected. The resulting samples were saturated xylan solution at $\mathrm{pH} 13$ (Xyl sol pH 13) and saturated xylan solution at $\mathrm{pH} 10$ (Xyl sol pH 10).

Ten grams of MCC (as bone dry) and $990 \mathrm{~g}$ of Xyl sol pH 13 or Xyl sol $\mathrm{pH} 10$ were stirred at room temperature for 7 days. The $\mathrm{pH}$ was recorded several times during this period.

After the adsorption, both of the samples were divided into two equal parts for further analysis.

A. Half of the sample was centrifuged resulting in the solid sample MCC + Xyl pH 13 unwashed and the supernatant (Sup Xyl pH 13). The same procedure was used for the samples at $\mathrm{pH} 10$. The solid sample was air-dried except a small portion (20\% of the original sample).

B. The other half was centrifuged and redispersed into $990 \mathrm{ml} \mathrm{pH}$ 13 water and centrifuged. This was repeated once more resulting in MCC + Xyl pH 13 washed. The same procedure was performed at $\mathrm{pH} 10$. The solid sample was air-dried except for a small portion ( $20 \%$ of the original sample).

Carbohydrate analysis of MCC, freeze-dried xylan and the four solid MCC + Xyl samples were performed after prehydrolysis with $72 \%$ $(\mathrm{w} / \mathrm{w})$ sulfuric acid for $60 \mathrm{~min}$ at $30^{\circ} \mathrm{C}$ and autoclaving at $4 \%(\mathrm{w} / \mathrm{w})$ sulfuric acid concentration for $60 \mathrm{~min}$ at $120^{\circ} \mathrm{C}$. The resulting monosaccharides were determined by high-performance anion-exchange chromatography (HPAEC) with pulse amperometric detection (Dionex ICS 3000 equipped with CarboPac PA1 column or Dionex ICS 5000 equipped with CarboPac PA20 column; Dionex, Sunnyvale, CA, USA) according to the NREL method (National Renewable Energy Laboratory). The carbohydrate analysis of Xyl sol pH 13 and Xyl sol

Table 1: Xylan and dry matter content of the xylan solutions/ dispersions for the adsorption trial.

\begin{tabular}{lrr}
\hline Sample & Xylan content $\left(\mathbf{g} \cdot \mathrm{l}^{-1}\right)$ & Dry matter content (wt.-\%) \\
\hline Xyl sol pH 13 & 9.22 & $2.20^{\mathrm{a}}$ \\
Xyl sol pH 10 & 11.19 & 1.27 \\
\hline
\end{tabular}

aThe sample contains significant amounts of sodium hydroxide from the $\mathrm{pH}$ regulation.

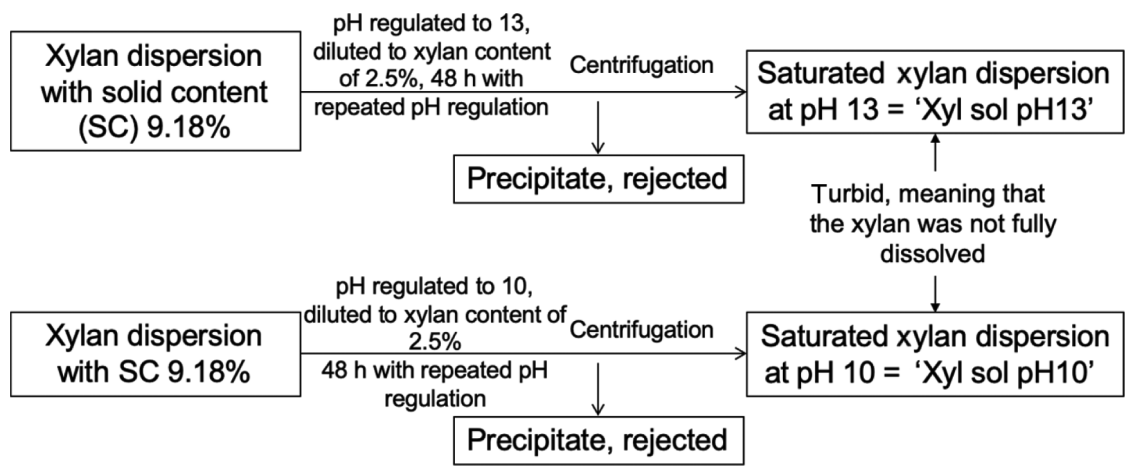

Figure 2: Schematic flow to obtain saturated xylan dispersion samples. 
$\mathrm{pH} 10$ was performed after neutralization using the same protocol but without prehydrolysis.

The carbohydrate composition, including neutral and acidic sugars, was determined according to Sundberg et al. (1996) with two parallel determinations.

Solid-state NMR experiments: The ${ }^{13} \mathrm{C}$ CPMAS NMR measurements were performed using an Agilent DD2 600 NMR spectrometer (Agilent Technologies, Santa Clara, CA, USA) with magnetic flux density of 14.1 T, equipped with a 3.2-mm T3 MAS NMR probe operating in a double resonance mode. The MAS rate in experiments was set to $10 \mathrm{kHz}$. For the CPMAS spectra of the reference materials, 8000 scans were accumulated using a 1.3-ms contact time and a 6.0-s delay between successive scans. The relaxation time constants $\mathrm{T}_{10}(\mathrm{H})$ for pure xylan and MCC were determined with a delayed contact pulse sequence to be $9.2 \mathrm{~ms}$ (xylan) and $18.5 \mathrm{~ms}$ (MCC). The clear difference in $\mathrm{T}_{10}(\mathrm{H})$ values indicates that the proton spin relaxation-based spectral edition (PSRE) for ordered MCC and amorphous xylan components can be carried out. The delayed contact pulse sequence was used also for the PSRE experiments with a duration for the spinlock pulse set as $8.0 \mathrm{~ms}$ for the partially relaxed spectra. Four thousand scans were collected for both relaxed and non-relaxed spectra. Protons were decoupled during acquisition using SPINAL-64 proton decoupling with a field strength of $80 \mathrm{kHz}$. Ninety-degree pulse durations and Hartmann-Hahn match for cross polarization were calibrated using $\alpha$-glycine. The spectra were processed using the TopSpin 3.5 software (Bruker Scientific Instruments, Billerica, MA, USA).

Adsorption of xylan on cellulose analyzed using QCM-D and AFM: Adsorption and desorption of xylan on cellulose was investigated using the E4 QCM-D instrument (Q-sense AB, Gothenburg, Sweden). QCM-D allows the simultaneous monitoring of changes in frequency and dissipation at the solid/liquid interface at the fundamental frequency of $5 \mathrm{MHz}$ and its six overtones. These changes are further translated to mass changes and changes in viscoelastic properties taking place during the adsorption/desorption process. The interpretation is described in detail in Rodahl et al. (1995). Briefly, when the adsorbed mass is evenly distributed, rigidly attached and fully elastic, the areal mass can be calculated according to the Sauerbrey equation (Sauerbrey 1959) where $\Delta m$ is the adsorbed mass per unit surface, $\Delta f=f-f_{0}$ is the frequency change, $n$ is the overtone number $(n=1,3,5$, $7,9,11,13$ ) and $C$ is the sensitivity constant of the device. In the present case, $C=0.177 \mathrm{mg} \cdot \mathrm{m}^{-2} \cdot \mathrm{Hz}^{-1}$ as reported by the supplier (Q-sense $\mathrm{AB}$ ).

$$
\Delta m=-\frac{C \Delta f}{n}
$$

If the material on the QCM-D sensor surface is not fully elastic, unevenly distributed or relatively thick, frictional losses occur that lead to a damping of the oscillation with the decay rate of amplitude that depends on the viscoelastic properties of the material. This is monitored by following the changes in dissipation energy, $D$, which is defined as follows:

$$
D=\frac{E_{\text {dissipation }}}{2 \pi E_{\text {storage }}}
$$

where $E_{\text {dissipation }}$ is the total dissipated energy during one oscillating cycle and $E_{\text {storage }}$ is the total energy stored in the oscillation.

Cellulose-coated thin films were deposited on gold QCM-D crystals by spincoating or by the Langmuir-Schaefer (LS) method using trimethylsilylcellulose (TMSC) (Kontturi et al. 2003; Tammelin et al.
Table 2: Sample set points (all sample points are at least duplicated).

\begin{tabular}{lr}
\hline Samples & $\begin{array}{r}\text { Xylan } \\
\text { concentration } \\
\left(\mathbf{m g} \cdot \mathbf{m l}^{-1}\right)\end{array}$ \\
\hline r1. pH $13 \mathrm{NaOH}$ solution with $1 \mathrm{mM} \mathrm{NaCl}$ (reference) & 0 \\
r2. $\mathrm{pH} 10 \mathrm{NaOH}$ solution with $1 \mathrm{mM} \mathrm{NaCl}$ (reference) & 0 \\
a1. pH $13 \mathrm{NaOH}$ solution with $1 \mathrm{mM} \mathrm{NaCl}$ & 0.01 \\
a2. pH $13 \mathrm{NaOH}$ solution with $1 \mathrm{mM} \mathrm{NaCl}$ & 0.1 \\
a3. pH $13 \mathrm{NaOH}$ solution with $1 \mathrm{mM} \mathrm{NaCl}$ & 1 \\
b1. pH $10 \mathrm{NaOH}$ solution with $1 \mathrm{mM} \mathrm{NaCl}$ & 0.01 \\
b2. pH $10 \mathrm{NaOH}$ solution with $1 \mathrm{mM} \mathrm{NaCl}$ & 0.1 \\
b3. pH $10 \mathrm{NaOH}$ solution with $1 \mathrm{mM} \mathrm{NaCl}$ & 1 \\
\hline
\end{tabular}

2006). Hexamethyl disilazane, dimetylacetamid (DMA) and litium chloride were purchased from Sigma-Aldrich, Finland. All other chemicals were analytic grade. LS surfaces were prepared on gold QDM-D sensors with polystyrene coating. Polystyrene $(0.1 \mathrm{w}-\%$, Mw $\left.280000 \mathrm{~g} \cdot \mathrm{mol}^{-1}\right)$ in toluene was first spincoated on the sensor (4000 rpm, $30 \mathrm{~s}$ ) and dried in an oven $\left(60^{\circ} \mathrm{C}\right.$ for $\left.10 \mathrm{~min}\right)$. TMSC was dissolved in chloroform $\left(0.4 \mathrm{mg} \cdot \mathrm{ml}^{-1}\right)$, and the 30 TMSC layers were deposited on the sensor using the LS method.

TMSC surfaces were regenerated to cellulose via desilylation in $10 \% \mathrm{HCl}$ vapor in vacuum for $5 \mathrm{~min}$ (Schaub et al. 1993).

TMSC was prepared from MCC powder (Fluka) by first dissolving in dimethylacetamide (DMAc)/LiCl followed by silylation with hexamethyl silazane (Cooper et al. 1981; Greber and Paschinger 1981). Successful silylation was evidenced by ${ }^{1} \mathrm{H}$ NMR in chloroform.

Prior to the adsorption studies, the cellulose surfaces were swollen in water overnight. The QCM-D sensors with cellulose thin films were placed in the QCM-D measurement cells, and the surfaces were allowed to stabilize in the appropriate buffer solution until a stable baseline was attained. Xylan dispersions were allowed to be adsorbed on the cellulose surfaces in the selected conditions which are shown in Table 2. After the measurement, the sample surfaces were rinsed with the given buffer solutions and dried by using nitrogen gas.

AFM microscopy: Changes in the topography of the cellulose surfaces before and after the xylan adsorption were monitored using AFM [ANASYS AFM $+{ }^{\circledR}$ (ANASYS Instruments Inc., Santa Barbara, CA USA)]. The AFM characterization was carried out in dry conditions directly after the QCM-D measurement. The images were taken in the tapping mode in air using aluminum-coated n-type silicon cantilevers (HQ:NSC15/Al BS, Micromasch, Tallinn, Estonia) with typical probe radius of $8 \mathrm{~nm}$, force constant of $40 \mathrm{~N} \cdot \mathrm{m}^{-1}$ and nominal resonance frequencies between 265 and $410 \mathrm{kHz}$. The images were not processed in any way except for flattening.

\section{Results and discussion}

\section{Preparation and characterization of the samples}

The xylan content was 9.22 and $11.19 \mathrm{~g} \cdot \mathrm{l}^{-1}$ for Xyl sol pH 13 and Xyl sol pH 10, respectively. This could not be 
calculated directly from the DMC and $\mathrm{pH}$ because the $\mathrm{NaOH}$ addition was not literally the amount necessary for adjusting aqueous solutions due to the buffering capacity of the xylan. It is interesting that more xylan remained dissolved or dispersed at $\mathrm{pH} 10$ compared to $\mathrm{pH} 13$. This phenomenon could not be studied in more detail in this work.

Adsorption experiments were performed using $10 \mathrm{~g}$ MCC (as bone dry) with $990 \mathrm{~g}$ of the Xyl sol pH13 and Xyl sol pH10, respectively. This means that approximately equal amounts of xylan and MCC were present in the experiments (xylan content of $9.13 \mathrm{~g}$ at $\mathrm{pH} 13$ and $11.08 \mathrm{~g}$ at $\mathrm{pH} 10)$. The $\mathrm{pH}$ was not adjusted after addition of xylan dispersions/solutions and mixing at room temperature for 7 days. For the experiment with Xyl sol pH 13, the final $\mathrm{pH}$ was 10.71 while for that with Xyl sol $\mathrm{pH} 10$, the final $\mathrm{pH}$ was 8.60. Most probably, also the MCC was buffering the $\mathrm{pH}$ together with the xylan. After 7 days, the samples were separated into two equal parts and centrifuged.

The solids from one-half were collected as such as "unwashed sample", and the wet yield and DMC were determined. The solids of the other half were washed with $\mathrm{pH}$-adjusted water and centrifuged again and this was repeated one more time. After that, the solids were collected ("washed sample"). Again, the wet yield and DMC were determined. A part of all samples was dried for carbohydrate analysis and NMR analysis, and the rest was stored wet.

The list of obtained samples with the yields and carbohydrate contents are given in Table 3. The xylan content was high in the MCC samples after adsorption at $\mathrm{pH} 13$ accounting for even $60 \%$ of the unwashed sample and $28 \%$ of the washed samples. This indicates a strong adsorption tendency that was only partly reversible during washing. During the adsorption trial, the $\mathrm{pH}$ decreased, which either enhanced the adsorption or was a consequence of it. At $\mathrm{pH} 10$, the xylan content was moderate with $7.6 \%$ in the unwashed sample and $2.5 \%$ in the washed sample, respectively.

The ratio of xylose to 4-methyl glucuronic acid was calculated based on the analysis data for the xylan sample used for fractionation as well as for the xylan dispersed at $\mathrm{pH} 10$. The ratios were 19 and 22, respectively. As the difference was only minor, uronic acid substitution is not expected to have a significant effect on solubility or dispersibility under these conditions.

\section{Adsorption of xylan on cellulose analyzed by NMR}

The solid-state NMR spectra for the reference materials, pure MCC and xylan are shown in Figure 3.

Each carbon atom in cellulose and xylan produces distinctive signals to the solid-state NMR spectrum according to their chemical environment in the molecule and to the level of molecular ordering. Due to similarity in the chemical structure of MCC and xylan, most of their solidstate ${ }^{13} \mathrm{C}$ NMR signals overlap. However, the signals from xylan carbon X1 at $100.46 \mathrm{ppm}$ and C4 carbon in ordered cellulose from crystalline interiors of MCC at $87.19 \mathrm{ppm}$

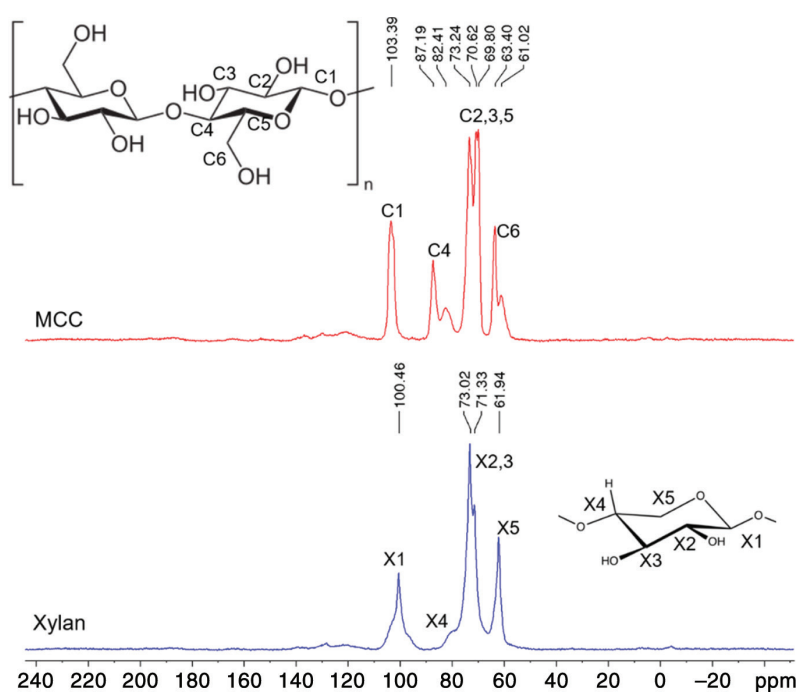

Figure 3: ${ }^{13} \mathrm{C}$ CPMAS NMR spectra of MCC and amorphous xylan reference samples.

Table 3: Yield of MCC samples with adsorbed xylan and polysaccharide contents.

\begin{tabular}{|c|c|c|c|c|c|c|}
\hline Sample & Wet yield (g) & DMC (\%) & Dry yield (g) & Cellulose (g) & Xylan (g) & Mannan (g) \\
\hline $\mathrm{MCC}+\mathrm{Xyl} \mathrm{pH} 13$ unwashed & $115.7^{\mathrm{a}}$ & 14.95 & 17.30 & 6.7 & 10.4 & 0.1 \\
\hline MCC + Xyl pH 13 washed & 34.0 & 8.89 & 3.02 & 2.14 & 0.85 & 0.04 \\
\hline MCC + Xyl pH 10 unwashed & $19.27^{\mathrm{b}}$ & 30.92 & 5.96 & 5.46 & 0.45 & 0.09 \\
\hline MCC + Xyl pH 10 washed & 14.76 & 27.54 & 4.06 & 3.89 & 0.10 & 0.06 \\
\hline
\end{tabular}

${ }^{\mathrm{a}} 50.8 \%$ of the wet sample; ${ }^{\mathrm{b}} 51.5 \%$ of the wet sample.

DMC, Dry matter content; MCC, microcrystalline cellulose. 


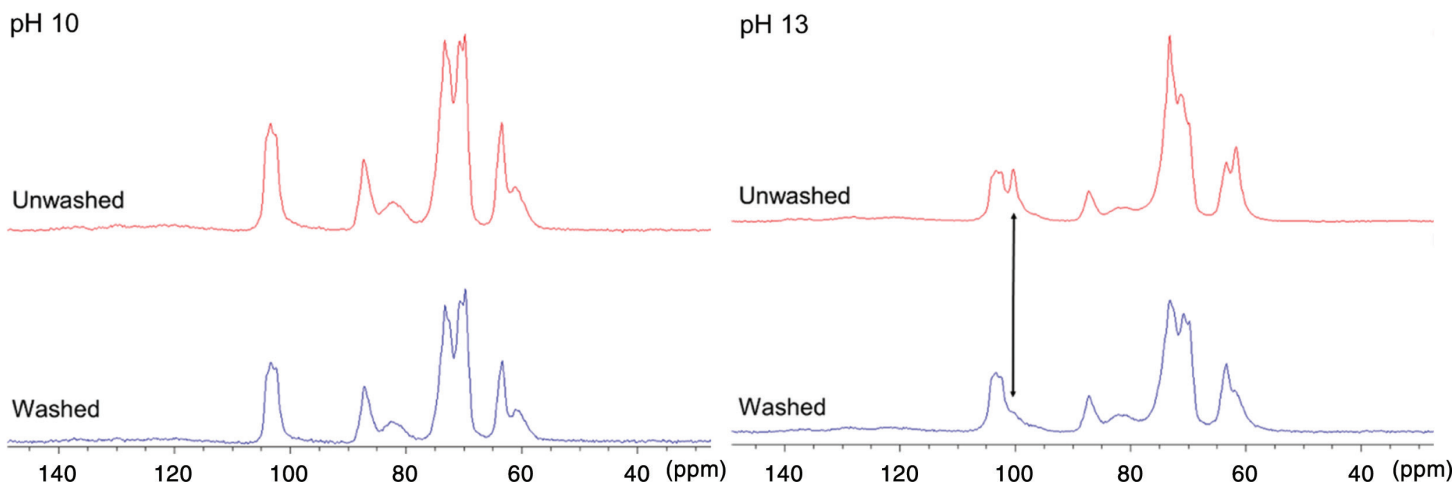

Figure 4: Solid-state ${ }^{13} \mathrm{C}$ NMR spectra of $\mathrm{MCC}+$ xylan samples prepared at different $\mathrm{pH}$ before and after the sample washing step. The arrow on the right-hand side figure marks the xylan $\mathrm{X} 1$ signal.

appear in the spectral regions with only partial overlap. These signals were chosen for spectral editing purposes to distinguish the ordered and less-ordered components into subspectra, as described later. The cellulose C4 signal at $82.2 \mathrm{ppm}$ is known to originate from somewhat less ordered fibril surfaces.

The NMR spectra for MCC samples with adsorbed xylan, before and after the washing step, are shown in Figure 4. It can be seen that in MCC $+\mathrm{Xyl} \mathrm{pH} \mathrm{10,} \mathrm{there}$ are no visible signals from xylan present. In contrast to this, there is a strong signal from xylan X1 observed close to the cellulose $\mathrm{C} 1$ in $\mathrm{MCC}+\mathrm{Xyl} \mathrm{pH}$ 13. The washing step decreases the intensity of the $\mathrm{X} 1$ signal, but it can still be observed in the spectrum as a shoulder on the cellulose C1 signal.

Figure 5 shows the result of PSRE in the case of MCC + Xyl pH 13 unwashed. The xylan subspectrum correlates well with the reference xylan spectrum. This suggests that xylan is precipitated mainly in an unordered form. There is also a clear xylan signal left in the MCC

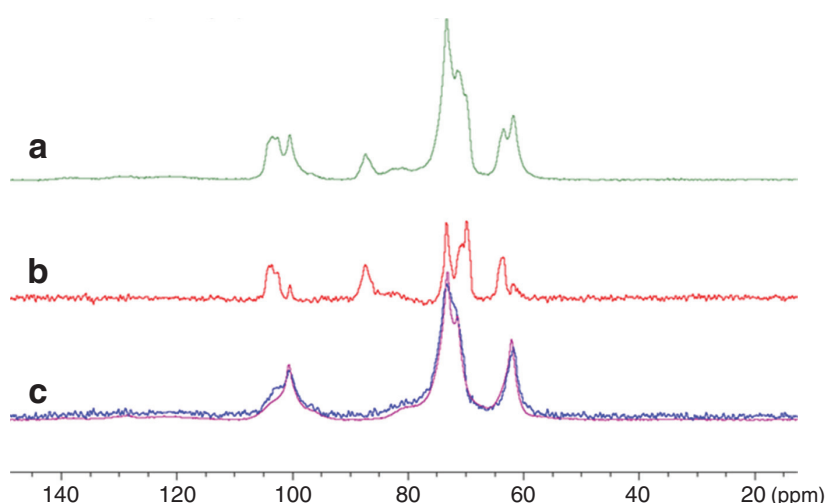

Figure 5: PSRE spectra of MCC + Xyl pH 13 unwashed.

(a) Original spectrum. (b) MCC sub spectrum. (c) Xylan subspectrum, together with the overlaid xylan reference spectrum (in purple). subspectrum at $100.4 \mathrm{ppm}$, representing a fraction closely associated with the ordered cellulose fibrils.

In the PSRE spectra of MCC + Xyl pH 13 washed (Figure 6), the remaining xylan does not contribute to the MCC subspectrum, which is assumed to represent the crystalline cellulose from the interiors of the crystallites. Xylan is observed in the subspectrum of less-ordered material, together with some cellulose signals, which most likely originate from the somewhat less ordered cellulose on the fibril surfaces, which apparently show similar relaxation behavior with xylan.

In the case of MCC + Xyl pH 10 unwashed (Figure 7), the only effect of PSRE appears to be a separation of cellulose signals into highly crystalline and less-ordered parts, the latter presumably originating from the fibril surfaces. The same result is obtained from the $\mathrm{MCC}+\mathrm{Xyl} \mathrm{pH}$ 10 washed (spectra not shown here).

According to CPMAS ${ }^{13} \mathrm{C}$ spectra, the amount of xylan in $\mathrm{MCC}+\mathrm{Xyl} \mathrm{pH} 10$ is below the detection limit of the experiment. In the MCC $+\mathrm{Xyl} \mathrm{pH} 13$, most of the xylan is in amorphous form, and not closely associated with

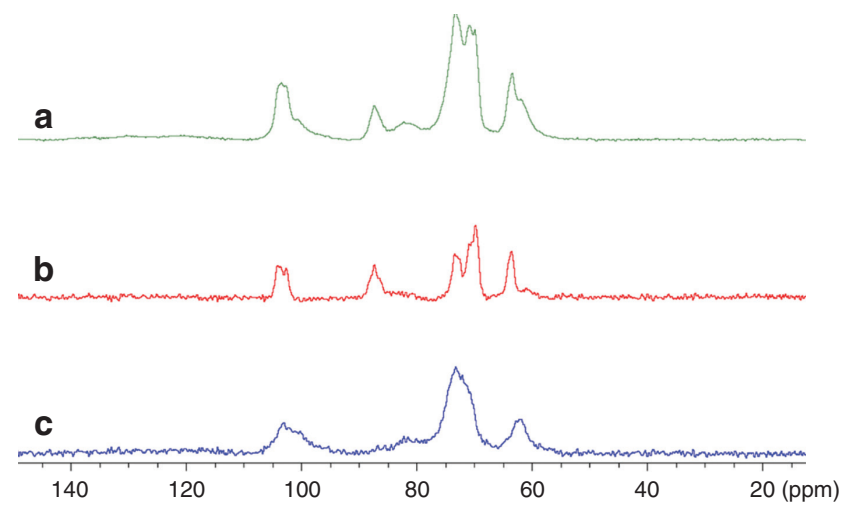

Figure 6: PSRE spectra of MCC $+\mathrm{Xyl}$ pH 13 washed.

(a) Original spectrum. (b) MCC sub spectrum. (c) Xylan subspectrum. 

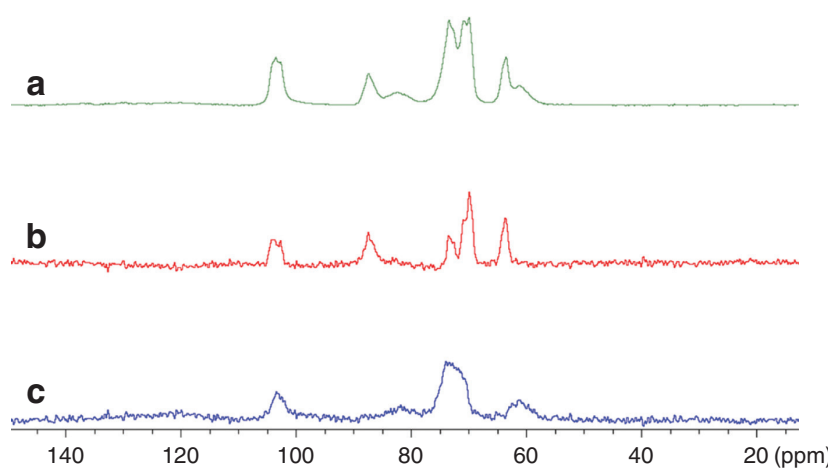

Figure 7: PSRE spectra of $\mathrm{MCC}+\mathrm{Xyl} \mathrm{pH} 10$ unwashed. (a) Original spectrum. (b) MCC subspectrum. (c) Xylan or less-ordered MCC subspectrum.

cellulose. However, part of the xylan that could not be removed by washing is closely associated with MCC and follows into the subspectrum of cellulose at fibril surfaces. Even though the fibril surfaces are less ordered than cellulose in the interiors of cellulose crystallites, it is more ordered compared to the amorphous isolated xylan, suggesting that the xylan associated with the fibril surfaces might also have an ordered conformation.

\section{Adsorption of xylan on cellulose analyzed by QCM-D and AFM}

The adsorption behavior of xylan on cellulose at high $\mathrm{pH}$ was investigated using surface-sensitive methods (QCM-D and AFM) to reveal the interactions taking place directly at the cellulose surface. At highly alkaline conditions ( $\mathrm{pH} 10$ and $\mathrm{pH} 13$ ), it is essential to follow and ensure the durability of the cellulose thin films which are deposited on the QCM-D sensor surfaces. Based on the preliminary tests, it was found that only highly crystalline cellulose surfaces prepared via the LS method were able to tolerate high alkaline conditions. More amorphous ultrathin films of cellulose produced via spincoating instantaneously dissolved when contacted with alkaline buffer solutions (results not shown). Furthermore, the most reliable adsorption experiments were produced at $\mathrm{pH} 10$ (LS-cellulose surfaces), and are therefore presented in the following.

Prior to the xylan adsorption experiments, the QCM-D sensors with cellulose thin films were first allowed to swell and stabilize overnight in milliQ water. Subsequently, the cellulose thin films were contacted with buffer solution $(1 \mathrm{mM} \mathrm{NaCl}$ at $\mathrm{pH} 10)$ until no changes in frequency and dissipation were detected, indicating that no changes due to swelling and/or cellulose dissolution occur (see Figure 8). As shown by Figure 8, the plateau level was

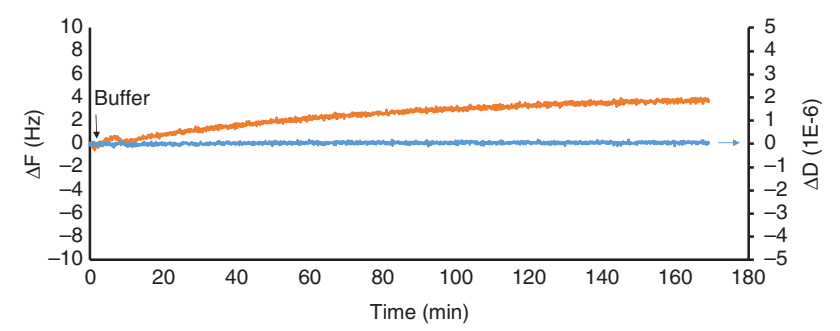

Figure 8: Changes in frequency (orange curve) and dissipation (blue curve) as a function of time recorded for LS-cellulose ultrathin films when stabilized and contacted with buffer solution of $\mathrm{pH} 10$ and $1 \mathrm{mM} \mathrm{NaCl}$. $\left(\mathrm{f}_{0}=5 \mathrm{MHz} n / 3\right)$.

attained after $150 \mathrm{~min}$ in contact with the buffer. A minor positive change in frequency indicates a corresponding loss of cellulose from the sensor surface. Such a small change in frequency $(<4 \mathrm{~Hz}$ corresponds to a mass change of $<0.7 \mathrm{mg} \cdot \mathrm{m}^{-2}$ calculated using the Sauerbrey equation) can be considered as a negligible mass loss and does not interfere in the following xylan adsorption experiments.

Figure 9 shows the adsorption isotherm of dissolved xylan on the cellulose surface using three concentration levels of xylan $\left(0.01 \mathrm{mg} \cdot \mathrm{ml}^{-1}, 0.1 \mathrm{mg} \cdot \mathrm{ml}^{-1}\right.$ and $\left.1 \mathrm{mg} \cdot \mathrm{ml}^{-1}\right)$ at $\mathrm{pH}$ 10. Again, the changes in frequency and dissipation as a function of time were followed in order to estimate the mass change due to xylan adsorption and to evaluate the physical properties of the formed xylan layers. Figure 9 clearly illustrates that significant xylan adsorption takes place only at the highest solution concentration of $1 \mathrm{mg} \cdot \mathrm{ml}^{-1}$, showing that xylan concentration has an important role in the deposition kinetics. Simultaneously, the dissipation change at the end of the adsorption was relatively high $\left(\sim 6.5 \times 10^{-6}\right)$, although the frequency change is as low as $-11 \mathrm{~Hz}$. This suggests that the formed xylan layer is not uniformly attached on the cellulose surface.

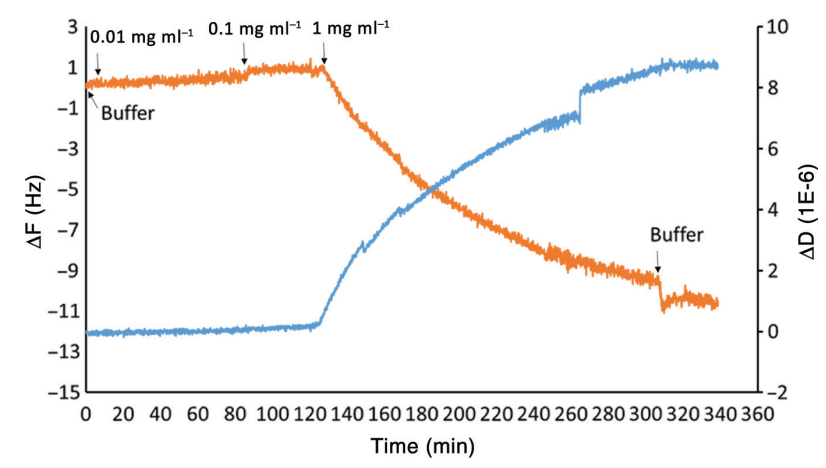

Figure 9: Adsorption isotherm of xylan from solutions containing $0.01 \mathrm{mg} \cdot \mathrm{ml}^{-1}, 0.1 \mathrm{mg} \cdot \mathrm{ml}^{-1}$ and $1 \mathrm{mg} \cdot \mathrm{ml}^{-1}$ of xylan in $\mathrm{pH} 10$ and $1 \mathrm{mM}$ $\mathrm{NaCl} . \Delta \mathrm{f}$ and $\Delta \mathrm{D}$ vs. time for $n=3$. 
Evenly distributed thin and rigidly attached polymer layer normally generates a dissipation change lower than $1 \times 10^{-6}$ with similar levels of frequency change. These findings are fully consistent with our previous results and are also supported by the AFM imaging (see Figure 10). After adsorbing xylan on cellulose, clear changes could be seen in both AFM height and phase contrast images (see Figure 10). Spherical xylan particles (Figure 10b and d) with the diameters varying between 0.01 and $0.1 \mu \mathrm{m}$ were seen. The height image of the reference cellulose surface is shown in Figure 10a. Our system here behaved exactly in the same way as discussed earlier (Paananen et al. 2004; Tammelin et al. 2009). The main driving force for xylan to adhere to the cellulose surface seems to be the poor solubility of xylan in aqueous solutions. High xylan concentration in solution restricts the solubility of the xylan chains and favors the formation of agglomerates. Attachment on the cellulose surface begins only when the concentration is relatively high, probably close to the limit of precipitation. In solution, polymer-polymer contacts dominate over polymer-solvent contacts, which promotes adsorption as xylan chains tend to escape from poor solvents. Chains either form agglomerates, get adsorbed on surfaces or even precipitate to avoid polymer-solvent contacts. Here, any precipitation was observed and care was taken to utilize freshly prepared xylan dispersions in all QCM-D experiments.

\section{Conclusions}

Adsorption of xylan from saturated solutions on MCC particles was successful, when starting from $\mathrm{pH}$ 13. A significant amount of xylan was strongly adsorbed and could not be removed by washing. Only minor irreversible enrichment of xylan was detected when the starting $\mathrm{pH}$
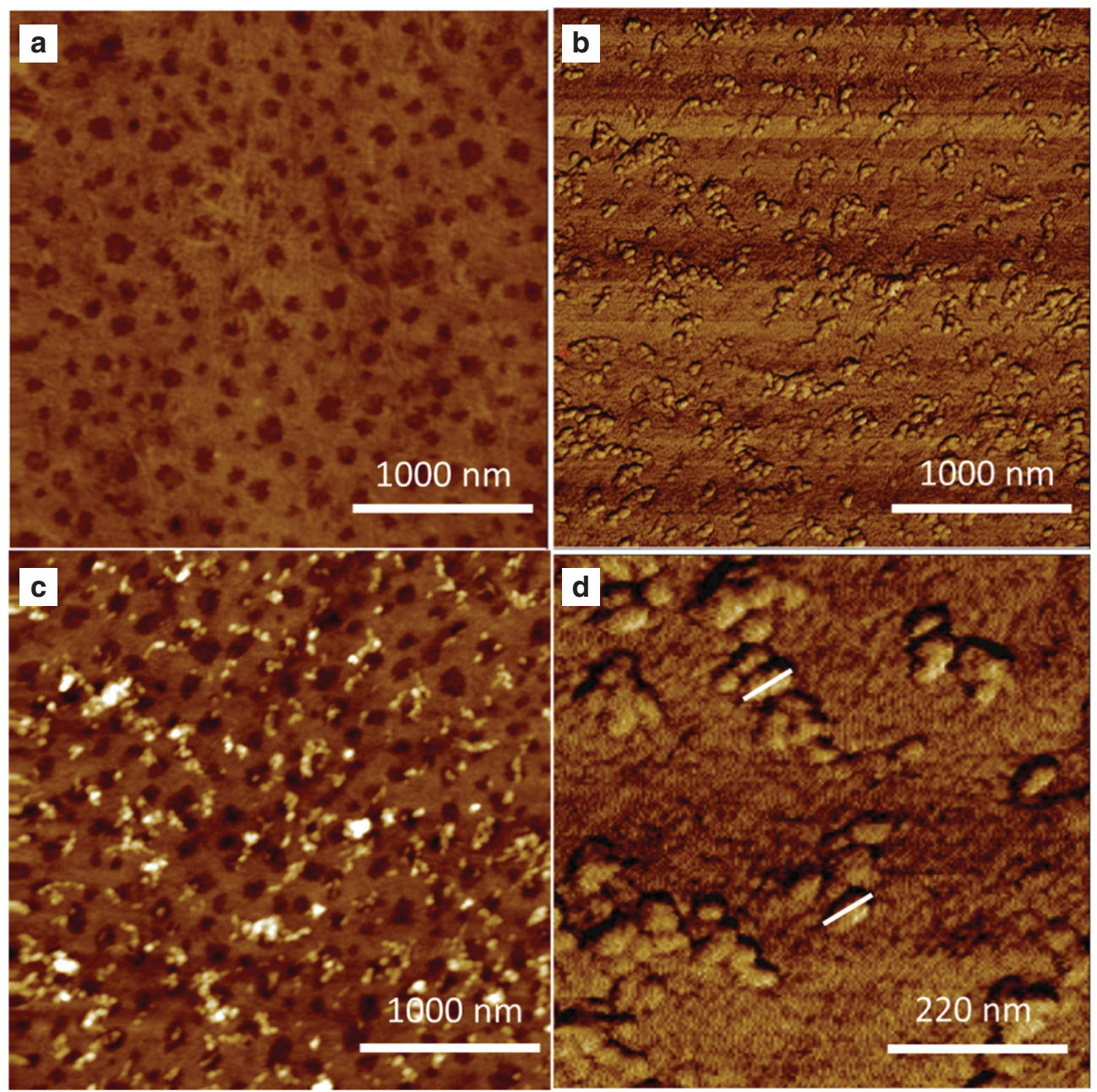

Figure 10: AFM images were taken for a better understanding of xylan and cellulose interaction and xylan behavior after during the deposition trials.

AFM height images of the cellulose surface before (a) and after (c) xylan adsorption. AFM phase image of the cellulose surface after xylan adsorption with two magnifications (b) and (d). 
was 10. The $\mathrm{pH}$ dropped during the 7-day adsorption time, indicating a buffering effect by the cellulose.

The xylan-adsorbed MCC samples before and after washing were analyzed by solid-state NMR. The amount of xylan in the MCC + Xyl pH 10 samples was below the detection limit of the experiment. In the MCC $+\mathrm{Xyl} p H$ 13 sample, the xylan was closely associated with MCC as it could not be completely separated from the MCC subspectrum. However, the washing step removed the xylan signal from the MCC subspectrum, while the remaining xylan signals were observed in the xylan subspectrum together with less-ordered cellulose signals, which are known to originate from the accessible fibril surfaces. This may indicate that the xylan fraction that remains after the washing step is closely associated with the surface of MCC. Therefore, through the use of NMR techniques, two distinct regions of xylan adsorption on cellulose fibers were possible to be seen. It suggests that there may be different adsorption mechanisms for each region, probably related to the size of the xylan fragment.

QCM-D experiments showed that xylan was irreversibly deposited on the cellulose surface, when the xylan concentration was high enough $\left(1 \mathrm{mg} \cdot \mathrm{ml}^{-1}\right)$. The AFM image of the formed surface indicated that xylan had deposited as oval particles with diameters around $0.01-0.1 \mu \mathrm{m}$, while most of the cellulose surface seems to be uncovered.

Acknowledgments: The authors thank Celulose Nipo-Brasileira S.A - CENIBRA for supporting this research. Atte Mikkelson (VTT) is thanked for the composition analyses.

Author contributions: All the authors have accepted responsibility for the entire content of this submitted manuscript and approved submission.

Research funding: This work was a part of the Academy of Finland's Flagship Programme under Projects No. 318890 and 318891 (Competence Center for Materials Bioeconomy, FinnCERES).

Employment or leadership: None declared.

Honorarium: None declared.

\section{References}

Alesiani, M., Proietti, F., Capuani, S., Paci, M., Fioravanti, M., Maraviglia, B. (2005) ${ }^{13}$ C CPMAS NMR spectroscopic analysis applied to wood characterization. Appl. Magn. Reson. 29:177-185.

Atalla, R.H., Vanderhart, D.L. (1984) Native cellulose: a composite of 2 distinct crystalline forms. Science 223:283-285.

Atalla, R.H., Hackney, J.M., Uhlin, I., Thompson, N.S. (1993) Hemicelluloses as structure regulators in the aggregation of native cellulose. Int. J. Biol. Macromol. 15:109-112.
Aurell, R. (1965) Increasing kraft pulp yield by redeposition of hemicelluloses. Tappi 48:80-84.

Axelsson, S., Croon, I., Enström, B. (1962) Dissolution of hemicelluloses during sulphate pulping. Sven. Papperstidn. 65:693-697.

Binnig, G., Quate, C.F., Gerber, C. (1986) Atomic force microscope. Phys. Rev. Lett. 56:930-933.

Bromley, J.R., Busse-Wicher, M., Tryfona, T., Mortimer, J.C., Zhang, Z., Brown, D.M., Dupree, P. (2013) GUX1 and GUX2 glucuronyltransferases decorate distinct domains of glucuronoxylan with different substitution patterns. Plant J. 74:423-434.

Busse-Wicher, M., Gomes, T.C.F., Tryfona, T., Nikolovski, N., Stott, K., Grantham, N.J., Bolam, D.N., Skaf, M.S., Dupree, P. (2014) The pattern of xylan acetylation suggests xylan may interact with cellulose microfibrils as a twofold helical screw in the secondary plant cell wall of Arabidopsis thaliana. Plant J. 79:492-506.

Busse-Wicher, M., Grantham, N.J., Lyczakowski, J.J., Nikolovski, N., Dupree, P. (2016a) Xylan decoration patterns and the plant secondary cell wall molecular architecture. Biochem. Soc. Trans. 44:74-78.

Busse-Wicher, M., Li, A., Silveira, R.L., Pereira, C.S., Tryfona, T., Gomes, T.C.F., Skaf, M.S., Dupree, P. (2016b) Evolution of xylan substitution patterns in gymnosperms and angiosperms: implications for xylan interaction with cellulose. Plant Physiol. 171:2418-243.

Chen, Q., Xu, S., Liu, Q., Masliyah, J., Xu, Z. (2016) QCM-D study of nanoparticle interactions. Adv. Colloid Interface Sci. 233:94-114.

Clayton, D.W., Phelps, G.R. (1965) The sorption of glucomannan and xylan on $\alpha$-cellulose wood fibres. J. Polym. Sci. 11:197-220.

Cooper, G.K., Sandberg, K.R., Hinck, J.F. (1981) Trimetylsilyl cellulose as precursor to regenerated cellulose fiber. J. Appl. Polym. Sci. 26:3827-3836.

Dahlman, O., Sjöberg, J., Jansson, U.B., Larsson, P.O. (2003) Effects of surface hardwood xylan on the quality of softwood pulps. Nord. Pulp Paper Res J. 18:310-315.

Dahlman, O., Jensen, A., Tormund, D., Östlund, J. (2008) Processing of xylan from hardwood spent cooking liquors. In: Conference proceedings from the Nordic Wood Biorefinery Conference, Sweden. pp. 114-119.

Danielsson, S., Lindström, M.E. (2005) Influence of birch xylan adsorption during kraft cooking on softwood pulp strength. Nord. Pulp Paper Res. J. 20:436-441.

Derjaguin, B. (1934) Friction and adhesion. IV. The theory of adhesion of small particles. Kolloid-Zeit 69:155-164.

Ducker, W.A., Senden, T.J., Pashley, R.M. (1991) Direct measurement of colloidal forces using an atomic force microscope. Nature 353:239-241.

Dupree, R., Simmons, T.J., Mortimer, J.C., Patel, D., luga, D., Brown, S.P., Dupree, P. (2015) Probing the molecular architecture of Arabidopsis thaliana secondary cell walls using two- and three-dimensional ${ }^{13} \mathrm{C}$ solid-state nuclear magnetic resonance spectroscopy. Biochemistry 54:2335-2345.

Dybowski, C., Bai, S. (2006) Solid-state nuclear magnetic resonance. Anal. Chem. 78:3853-3858.

Eriksson, E., Sjöström, E. (1968) Influence of acidic groups on the physical properties of high-yield pulps. Tappi 51:56-59.

Eriksson, E., Samuelson, O., Viale, A. (1963) Adsorption of hemicellulose isolated from sulfite cooking liquors by cellulose fibers. Sven. Papperstidn. 66:403-406.

Fatisson, J., Domingos, R.F., Wilkinson, K.J., Tufenkji, N. (2009) Deposition of $\mathrm{TiO}_{2}$ nanoparticles onto silica measured using 
a quartz crystal microbalance with dissipation monitoring. Langmuir 25:6062-6069.

Ghisalberti, E.L., Godfrey, I.M. (1998) Application of nuclear magnetic resonance spectroscopy to the analysis of organic archaeological materials. Stud. Conserv. 43:215-230.

Greber, G., Paschinger, O. (1981) Silyl derivatives of cellulose. Das Papier 35:547-554.

Hansson, J.-Å. (1970) Sorption of hemicelluloses on cellulose fibres. Part 3. The temperature dependence on sorption of birch xylan and pine glucomannan at kraft pulping conditions. Sven. Papperstidn. 73:49-53.

Hansson, J.-Å., Hartler, N. (1969) Sorption of hemicelluloses on cellulose fibres. Part 1. Sorption of xylans. Sven. Papperstidn. 72:521-530.

Hult, E.-L., Larsson, P.T., Iversen, T. (2000) A comparative CP/MAS ${ }^{13}$ CNMR study of cellulose structure in spruce wood and kraft pulp. Cellulose 7:35-55.

Janzon, R., Puls, J., Saake, B. (2006) Upgrading of paper-grade pulps to dissolving pulps by nitren extraction: optimization of extraction parameters and application to different pulps. Holzforschung 60:347-354.

Kleppe, P. (1970) Kraft pulping. Tappi 53:35-47.

Kontturi, E., Thune, P.C., Niemantsverdriet, J.W. (2003) Cellulose model surfaces: simplified preparation by spin coating and characterization by X-ray photoelectron spectroscopy, infrared spectroscopy, and atomic force microscopy. Langmuir 19:5735-5741.

Kontturi, E., Tammelin, T., Österberg, M. (2006) Cellulose-model films and the fundamental approach. Chem. Soc. Rev. 35:1287-1304.

Korolkov, V.V., Summerfield, A., Murphy, A., Amabilino, D.B., Watanabe, K., Taniguchi, T., Beton, P. (2019) Ultra-high resolution imaging of thin films and single strands of polythiophene using atomic force microscopy. Nat Commun 10:1537-1545.

Krogerus, B., Fuhrmann, A. (2009) Isolation of xylan and use as wet end- and binder chemical. In: Conference Proceedings from the 15th International Symposium on Wood, Fibre and Pulping Chemistry, Oslo, Norway, 15-18 June. pp. 110.

Laine, C., Kemppainen, K., Kuutti, L., Varhimo, A., Asikainen, S., Grönroos, A., Määttänen, M., Buchert, J., Harlin, A. (2015) Extraction of xylan from wood pulp and brewer's spent grain. Ind. Crop. Prod. 70:231-237.

Lambert, J.B., Shawl, C.E., Stearns, J.A. (2000) Nuclear magnetic resonance in archaeology. Chem. Soc. Rev. 29:175-182.

Larsson, P.T., Wickholm, K., Iversen, T. (1997) A CP/MAS ${ }^{13}$ C NMR investigation of molecular ordering in celluloses. Carbohydr. Res. 302:19-25.

Larsson, P.T., Hult, E.-L., Wickholm, K., Pettersson, E., Iversen, T. (1999) CP/MAS ${ }^{13}$ C-NMR spectroscopy applied to structure and interaction studies on cellulose I. Solid State Nucl. Magnet. Resonan. 15:31-40.

Li, J., Zhang, H., Duan, C., Liu, Y., Ni, Y. (2015) Enhancing hemicelluloses removal from a softwood sulfite pulp. Bioresour. Technol. 192:11-16.

Linder, A., Bergman, R., Bodin, A., Gatenholm, P. (2003) Mechanism of assembly of xylan onto cellulose surfaces. Langmuir 19:5072-5077.

Lindgren, T., Edlund, U., Iversen, T. (1995) A multivariate characterization of crystal transformations of cellulose. Cellulose 2:273-288.
Maunu, S., Liitiä, T., Kauliomäki, S., Hortling, B., Sundquist, J. (2000) ${ }^{13}$ C CPMAS NMR investigations of cellulose polymorphs in different pulps. Cellulose 7:147-159.

Miao, Q., Chen, L., Huang, L., Tian, C., Zheng, L., Ni, Y. (2014) A process for enhancing the accessibility and reactivity of hardwood kraft-based dissolving pulp for viscose rayon production by cellulase treatment. Bioresour. Technol. 154:109-113.

Mitikka-Eklund, M. Sorption of Xylans on Cellulose Fibers. University of Jyväskylä, Finland, 1996.

Mobarak, F., El-Ashawy, A.E., Fahmy, Y. (1973) Hemicelluloses as additive in papermaking. Part 2. The role of added hemicellulose in situ on paper properties. Cellulose Chem. Technol. 7:325-335.

Mocchiuttia, P., Schnella, C.N., Rossia, G.D., Peresinb, M.S., Zanuttinia, M.A., Galvána, M.V. (2016) Cationic and anionic polyelectrolyte complexes of xylan and chitosan. Interaction with lignocellulosic surfaces. Carbohydr. Polym. 150:89-98.

Mora, F., Ruel, K., Comtat, J., Joseleau, J.P. (1986) Aspects of native and redeposited xylans at the surface of cellulose microfibrils. Holzforschung. 40:85-91.

Newman, R.H. (1992) Nuclear magnetic resonance study of spatial relationships between chemical components in wood cell walls. Holzforschung 46:205-210.

Newman, R.H. (1998) Evidence for assignment of ${ }^{13} \mathrm{C}$ NMR signals to cellulose crystallite surfaces in wood, pulp and isolated celluloses. Holzforschung 52:157-159.

Newman, R.H., Hemmingson, J.A. (1990) Determination of the degree of cellulose crystallinity in wood by carbon-13 nuclear magnetic resonance spectroscopy. Holzforschung 44:351-355.

Newman, R.H., Hemmingson, J.A., Suckling, I.D. (1993) Carbon-13 nuclear magnetic resonance studies of kraft pulping. Holzforschung 47:234-238.

Paananen, A., Österberg, M., Rutland, M., Tammelin, T., Saarinen, T., Tappura, K., Stenius, P. (2004) Interaction between cellulose and xylan: an atomic force microscope and quartz crystal microbalance study. In: Hemicelluloses: Science and technology. ACS Symposium Series 864. Eds. Gatenholm, P., Tenkanen, M. pp. 269-290.

Pournou, A. (2008) Deterioration assessment of waterlogged archaeological lignocellulosic material via ${ }^{13} \mathrm{C} \mathrm{CP} / \mathrm{MAS} N M R$. Archaeometry 50:129-141.

Ribe, E., Wernersson, F., Theliander, H. (2009) Optimal industrial birch black liquor for xylan sorption. In: Tappi Engineering, Pulping and Environmental Conference, Tappi Press, USA. 19.3.

Rodahl, M., Höök, F., Krozer, A., Brzezinski, P., Kasemo, B. (1995) Quartz crystal microbalance setup for frequency and Q-factor measurements in gaseous and liquid environments. Rev. Sci. Instrum. 66:3924-3930.

Santonia, I., Calloneb, E., Sandaka, A., Sandaka, J., Dirèb, S. (2015) Solid-state NMR and IR characterization of wood polymer structure in relation to tree provenance. Carbohydr. Polym. 117:710-721.

Sauerbrey, G.Z. (1959) Verwendung von Schwingquarzen zur Wägung dünner Schichten und zur Mikrowägung. Physik 155:206.

Schaub, M., Wenz, G., Wegner, G., Stein, A., Klemm, D. (1993) Ultrathin films of cellulose on silicon wafers. Adv. Mater. 5:919-922.

Schönberg, C., Oksanen, T., Suurnäkki, A., Kettunen, H., Buchert, J. (2001) The importance of xylan for the strength properties of spruce kraft fibres. Holzforschung 55:639-644.

Sihtola, H., Blomberg, L. (1975) Hemicelluloses precipitated from steeping liquor in the viscose process as additives in papermaking. Cell. Chem. Technol. 9:555-560. 
Simonson, R. (1963) The hemicellulose in the sulphate pulping process. I. Isolation of hemicellulose fractions from sulphate cooking liquors. Sven. Papperstidn. 66: 839-845.

Simmons, T.J., Mortimer, J.C., Bernardinelli, O.D., Pöppler, A., Brown, S.P., Azevedo, E.R., Dupree, R., Dupree, P. (2016) Folding of xylan onto cellulose fibrils in plant cell walls revealed by solid-state NMR. Nat. Commun. 7:1-9.

Sjöström, E. Wood Chemistry, Fundamentals and Applications. Academic Press, New York, 1981.

Sjöström, E., Enström, B. (1967) Characterization of acidic polysaccharides isolated from different pulps. Tappi 50:32-36.

Soares, M.C.D.S.M. Métodos Alternativos para Deposição de Xilanas em Polpas de Eucalipto. Universidade Federal de Viçosa, Brazil, 2009.

Srndovic, J.S. Interactions between Wood Polymers in Wood Cell Walls and Celulose/Hemicellulose Biocomposites. Chalmers University of Technology, Sweden, 2011.

Sundberg, A., Sundberg, K., Lillandt, C., Holmbom, B.R. (1996) Determination of hemicelluloses and pectins in wood and pulp fibres by acid methanolysis and gas chromatography. Nord. Pulp Paper Res. J. 11:216-219.

Tammelin, T., Saarinen, T., Österberg, M., Laine, J. (2006) Preparation of Langmuir/Blodgett-cellulose surfaces by using horizontal dipping procedure. Application for polyelectrolyte adsorption studies performed with QCM-D. Cellulose 13: 519-535.

Tammelin, T., Paananen, A., Österberg, M. (2009) Hemicelluloses at interfaces: some aspects on the interactions In: The Nanoscience and Technology of Renewable Biomaterials, Eds. Lucia, A.L., Rojas, O.J. Wiley-Blackwell Publishing Ltd, West Sussex, UK. pp. 149-172.

Thio, B.J.R., Zhou, D., Keller, A.A. (2011) Influence of natural organic matter on the aggregation and deposition of titanium dioxide nanoparticles. J. Hazard. Mater. 189:556-563.

Timell, T.E. (1967) Recent progress in the chemistry of wood hemicelluloses. Wood Sci. Technol. 1:45-70.

Vaaler, D., Ljones, S., Ribe, E., Toven, K., Moe, S. (2002) Effects of hemicellulose stabilisation and raw material on the beatability of softwood kraft pulps. In: 7th EWLP, Åbo Akademi University, Turku, Finland. pp. 147-150.

Van der Hart, D.L., Atalla, R.H. (1984) Studies of microstructures in native celluloses using solid-state ${ }^{13} \mathrm{C}$ NMR. Macromolecules 17:1465-1472.

Wickholm, K., Larsson, P.T., Iversen, T. (1998) Assignment of noncrystalline forms in cellulose I by CP/MAS ${ }^{13} \mathrm{C}$ NMR spectroscopy. Carbohydr. Res. 312:123-129.

Yllner, S., Enström, B. (1956) Studies of the adsorption of xylan on cellulose fibers during the sulphate cook. Part 1 . Sven. Papperstidn. 59:229-232. 